The novelties and research highlights of this work are briefly summarized below:

- A detailed experimental procedure has been developed for the synthesis of aliphatic urethane-based shape memory polymers (SMPs).

- Comprehensive thermomechanical characterizations on a variety of SMP compositions have been performed to investigate the key connections between the polymer's working temperature, thermal stability and their mechanical behavior.

- Recovery tests have also been conducted for demonstrating the superb shape memory and recovering features of the SMPs which is desirable for the endovascular embolization procedure.

- A range of SMP compositions that most accurately meet our criteria have been identified in this study with their great potential for the individualized treatment of intracranial aneurysms, which will be analyzed further in more detail as a part of future studies. 

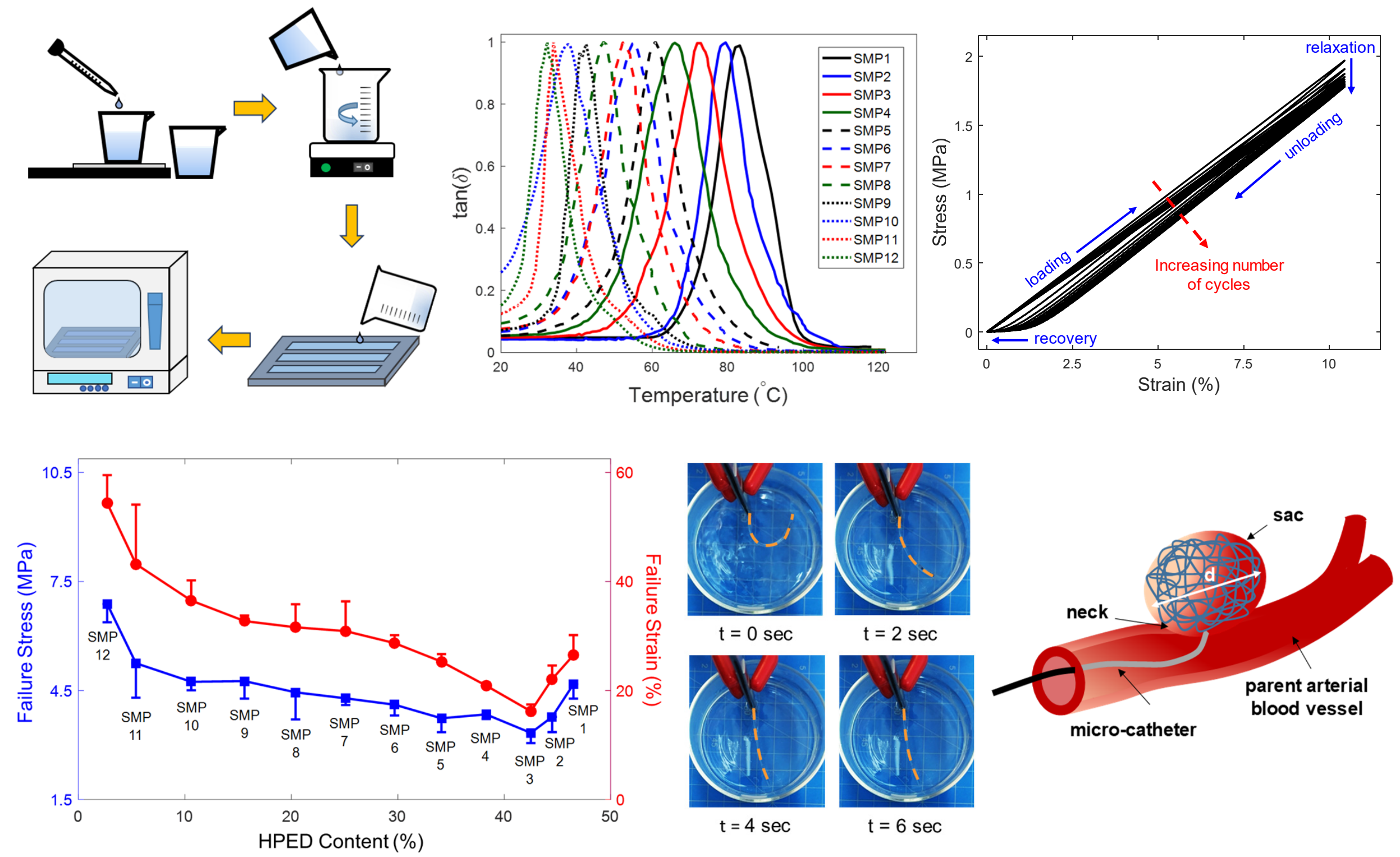

$\mathrm{t}=4 \mathrm{sec}$

$\mathrm{t}=6 \mathrm{sec}$

micro-catheter 


\title{
Synthesis and characterization of bio-compatible shape memory polymers with potential applications to endovascular embolization of intracranial aneurysms
}

\author{
Robert Kunkel ${ }^{1}$, Devin Laurence ${ }^{1 *}$, Jingyu Wang ${ }^{1}$, Donnie Robinson ${ }^{1}$, Joshua Scherrer ${ }^{1}$, \\ Yi Wu' ${ }^{1}$, Bradley N. Bohnstedt², Aichi Chien ${ }^{3}$, Yingtao Liu' ${ }^{1}$, and Chung-Hao Lee ${ }^{1,4}$ \\ ${ }^{1}$ School of Aerospace and Mechanical Engineering \\ The University of Oklahoma \\ Norman, OK 73019, USA \\ 2Department of Neurosurgery \\ The University of Oklahoma Health Sciences Center \\ Oklahoma City, OK 73104, USA \\ ${ }^{3}$ Division of Interventional Neuroradiology \\ Department of Radiology \\ University of California, Los Angeles (UCLA) Medical School \\ Los Angeles, CA 90095 \\ ${ }^{4}$ Instiute for Biomedical Engineering, Science and Technology \\ The University of Oklahoma \\ Norman, OK 73019, USA \\ ${ }^{\star}$ Equal $1{ }^{\text {st_-Authored Contribution }}$
}

August 22, 2018

For correspondence:

Chung-Hao Lee, Ph.D.

Assistant Professor

School of Aerospace and Mechanical Engineering

Affiliated Faculty Member

Institute for Biomedical Engineering, Science, and Technology

The University of Oklahoma

865 Asp Ave., Felgar Hall Rm. 219C

Norman OK 73019-3609

email:ch.lee@ou.edu

Tel: 405-325-4842 


\section{Abstract}

Intracranial aneurysms (ICAs) are focal dilations in the brain's arteries. When left untreated, ICAs can grow to the point of rupture, accounting for $50-80 \%$ of subarachnoid

4 hemorrhage cases. Current treatments include surgical clipping and endovascular coil 5 embolization to block circulation into the aneurysmal space for preventing aneurysm rupture. As 6 for endovascular embolization, patients could experience aneurysm recurrence due to an 7 incomplete coil filling or compaction over time. The use of shape memory polymers (SMPs) in 8 place of conventional platinum coils could provide more control and predictability for mitigating 9 these complications. This study was focused on characterization of an aliphatic urethane-based 10 SMP to evaluate its potential as a novel biomaterial for endovascular embolization. Twelve 11 compositions of the SMP were synthesized and their thermomechanical properties together with 12 the shape recovery behavior were comprehensively investigated. Our results showed that the 13 SMPs experienced a significant decrease in storage and loss moduli as heated above their glass 14 transition temperatures $\left(32.3^{\circ} \mathrm{C}-83.2^{\circ} \mathrm{C}\right)$, and that all SMPs were thermally stable up to $265^{\circ} \mathrm{C}$. 15 Moreover, the SMPs exhibited both composition-dependent stress relaxation and a decrease in 16 elastic modulus during cyclic loading. The shape recovery time was less than 11 seconds for all 17 SMP compositions, which is sufficiently short for shape changing during embolization 18 procedures. Several candidate compositions were identified, which possess a glass transition 19 temperature above body temperature $\left(37^{\circ} \mathrm{C}\right)$ and below the threshold of causing tissue damage $20\left(45^{\circ} \mathrm{C}\right)$. They also exhibit high material strength and low stress relaxation behavior, suggesting 21 their potential applicability to endovascular embolization of ICAs.

22 Keywords: Shape memory polymers; polyurethane; glass transition temperature; thermo23 mechanical properties; endovascular embolization 


\section{Introduction}

An intracranial aneurysm (ICA), or a cerebral aneurysm, is an abnormal focal dilation and weakening of an arterial blood vessel in the brain with a prevalence of $0.5 \%-6 \%$ in adults (Rinkel et al., 1998; Schievink, 1997). Although most aneurysms are asymptomatic and do not rupture, they can grow unpredictably, and even small aneurysms (size $\leq 5.0 \mathrm{~mm}$ ) carry a risk of rupture. Incidental rupture of an ICA is most common between age 40 and 65 , associated with $50 \%-80 \%$ of the subarachnoid hemorrhage (SAH) cases, which causes individual's death before receiving medical attention associated with a mortality rate as high as $40 \%$ within the first week, and accounts for about 5\%-8\% of all strokes, (Bederson et al., 2009; Connolly et al., 2012; King Jr, 1997; Lantigua et al., 2015; Naval et al., 2012; Sacco et al., 1984; Wardlaw and White, 2000).

Currently, surgical clipping and endovascular coil embolization are the two most common treatment methods for intracranial aneurysms. Clipping of intracranial aneurysms requires craniotomy and neurosurgeon places a clip across the neck of the treated aneurysm to block it from the normal circulation (Molyneux et al., 2005). In contrast, micro-catheter delivery-based endovascular therapy with Guglielmi detachable coils (GDC) (Guglielmi et al., 1991; Molyneux and Group, 2002; Raymond et al., 2003) is a minimally invasive surgical technique, which aims at excluding the aneurysmal sac and neck from intracranial circulation by means of complete and lasting occlusion. Although GDC-based coil embolization therapy has been considered as an alternative to surgical clip ligation that is associated with higher procedural mortality (Campi et al., 2007; Molyneux et al., 2009; Taha et al., 2006), recent studies (Hope et al., 1999; Tateshima et al., 2000; Vallée et al., 2003; Wehman et al., 2006) have shown that unsatisfying rates of aneurysmal recanalization and incomplete occlusion are still emerging challenges in endovascular coil embolization. Therefore, development of novel biomedical devices for the use in minimally invasive surgical procedures as tailored to patient's complex aneurysm geometry is essential to improve the long-term therapeutic outcomes of current endovascular techniques and to overcome the above-mentioned clinical challenges.

As the first logical step towards the attainment of this research objective, we, in this study, comprehensively characterize the thermomechanical properties and the shape recovery capability of aliphatic urethane shape memory polymers (SMPs) and investigate its potential 53 applications to manufacturing individualized embolic devices for treating intracranial aneurysms. 54 Shape memory polymers, such as polyurethane (Gunes et al., 2008; Xu et al., 2006), have aroused great attention from scientists and engineers owing to their excellent shape memory 
56 behavior, high biocompatibility, fast shape recovery speed, and low synthesis cost. This type of 57 polymer is synthesized using hexamethylene diisocyanate (HDI), N,N,NO,NO-tetrakis 58 (hydroxypropyl) ethylenediamine (HPED), and Triethanolamine (TEA), and consists of two 59 segments at the molecular level: (1) the rigid and glassy segments determining the permanent 60 shape and (2) the amorphous segments controlling the temporary shape. Currently, most of the 61 biocompatible SMPs used for biomedical applications are thermally induced. When heated 62 above its glass transition temperature $\left(T_{g}\right)$, the amorphous segments of the SMP transition from 63 a glassy state to a rubbery state, allowing the polymer to deform under an external load (Huang 64 et al., 2012). After cooling below $T_{g}$ and subsequent releasing of the external loading, the 65 temporary shape is obtained. The polymer can autonomously return to this programmed shape without external mechanical stimuli when polymer temperature increases above $T_{g}$ again.

Biomedical devices fabricated using SMPs can potentially be introduced into a patient's body in a temporary, compressed shape and then be expanded on demand to their programmed shape as required. Since the shape recovery can be facilitated with a certain triggering mechanism, such as increasing temperature, the release of medical devices can be completed without additional complex surgical operations, but rather through the micro-catheter. Many biomedical devices and applications have been developed for SMPs that allow triggered responses, including self-tightened biodegradable sutures (Lendlein and Langer, 2002), a microactuator for blood removal (Maitland et al., 2002), and stents (Wache et al., 2003).

In this study, we aim to develop a detailed experimental procedure for the synthesis of aliphatic urethane based SMPs and perform comprehensive thermomechanical characterization on a range of SMP compositions to investigate connections between the working temperature of the polymers and their mechanical behavior. Specifically, we identify the glass transition temperatures of each composition using both dynamic mechanical analysis (DMA) and differential scanning calorimetry (DSC) tests, and we determine the threshold for thermal degradation of each composition using thermogravimetric analysis (TGA). We also report the 82 results of uniaxial cyclic and failure testing and analyze the differences in behavior between different compositions. We conduct this research with the goal of eventually designing an advanced individualized endovascular embolization device using aliphatic urethane SMPs as 85 the primary material. Consequentially, we discuss the results in terms of the desirable physical qualities such an implantable material that would need to possess. 


\section{Methods}

2.1 Materials and SMP synthesis

In this work, (i) hexamethylene diisocyanate ( $\mathrm{HDI}, \geq 99.0 \%$ ), (ii) $\mathrm{N}, \mathrm{N}, \mathrm{NO}, \mathrm{NO}$-tetrakis (hydroxypropyl) ethylenediamine (HPED, $\geq 98.0 \%$ ), and (iii) Triethanolamine (TEA, $\geq 99.0 \%$ ) were purchased from Sigma-Aldrich. All the above materials were used as received for synthesizing aliphatic urethane shape memory polymers. Twelve combinations of these three monomers were synthesized, with their respective SMP formulations given in Table 1.

\subsection{SMP synthesis procedure}

Various SMPs were synthesized by mixing different ratios of HPED, TEA, and HDI. The molar ratios for each batch were sourced from the previous study by Wilson et al. (Wilson et al., 2007) with modifications to the second and last compositions (Table 1). All measurement and mixing procedures occurred within a nitrogen-filled glovebox to avoid moisture contamination of the monomers (Fig. 1a). The glovebox received a steady flow of nitrogen through an inlet at the top of the rear panel and vented gas into a fume hood from an outlet at the bottom of the rear panel. This prevented air from entering the work space and removed any undesired moisture prior to the synthesis. Nitrogen flow could be redirected to the vacuum oven used later during synthesis via a set of ball valves.

Monomer weighing was performed using a Fisherbrand motorized pipette filler (Thermo Fisher Scientific) and a digital scale (AWS-100, American Weigh Scales). In brief, the HPED and TEA were measured in the same $100 \mathrm{~mL}$ glass beaker, while HDI was kept in a separate container until the stirring stage where it was added to the mixture and stirred on a magnetic stirring plate (Fig. 1b). The mixture was stirred gently to avoid the introduction of gas bubbles into the liquid. Stirring continued until the mixture showed a sudden transition from translucent to uniformly clear. The time required to produce this transition increased as the ratio of HPED in the mixture decreased and the ratio of HDI increased (Table 1).

The procedures in Wilson et al. (Wilson et al., 2007) suggested including an excess of $1-2 \%$ isocyanate $(\mathrm{HDI})$. However, our early synthesis results were unsatisfactory, and the removal of this excess improved the success rate of our syntheses. We also observed a tendency of the mixtures to cure before degassing could take place, leaving large air bubbles in the resulting specimens. Since the mixture of the monomers is an exothermic reaction, we noticed large batches of the mixture could generate adequate heat to act as a catalyst for the curing process. To avoid these scenarios, we limited the size of each batch to $16 \mathrm{~g}-18 \mathrm{~g}$, and 
119 mixed multiple small batches during a single synthesis procedure, rather than mixing the full 120 volume all at once.

121 Once the mixture had sufficiently reacted, we quickly removed it from the glovebox and 122 poured the contents into a set of silicone rubber molds-rectangular beams $(45 \mathrm{~mm} \times 8 \mathrm{~mm} \times$ $1231 \mathrm{~mm}$ ) for glass transition-related characterizations and ASTM D638 Type V dog bones for tensile 124 mechanical testing (c.f. Sections 2.3 and 2.4, respectively). Prior to the synthesis, two coats of 125 mold release (Buehler 208186032) were applied to each specimen mold to minimize bubble 126 generations due to any undesired interactions between the mixed monomers and the silicone 127 rubber during curing. Then, specimen molds were placed in a vacuum oven (Being BOV-20) and 1285 vacuuming (-0.8 bar) and nitrogen purging steps were performed to create a nitrogen protected 129 environment in the oven before degassing. A strong vacuum (-0.925 bar) was next induced using 130 a vacuum pump for 10-12 minutes to remove gas bubbles trapped in the mixture (Fig. 1a-b). 131 For cases where multiple batches of mixture were used, we filled each mold half way with mixture 132 and performed an initial degassing step while mixing the other batch. When the first degassing 133 had finished, we filled the rest of the space of the molds and proceeded with the above134 mentioned vacuuming-purging and degassing steps. An "overflow" section was included in our 135 specimen molds to trap bubbles as introduced during the degassing procedure. The top few 136 millimeters of each specimen could be polished off to leave a smooth finishing.

137 When curing the SMP specimens, we followed the procedure in Wilson el at. (Wilson et 138 al., 2007) with several modifications. The specimens were kept at room temperature for one 139 hour, then the temperature was increased at a steady rate to $130^{\circ} \mathrm{C}$, where it was kept for 140 another hour. The heating rate of temperature was proportional to the glass transition 141 temperature $\left(\mathrm{T}_{\mathrm{g}}\right)$ of the specimen being cured, to ensure each SMP had an equal curing time 142 before reaching its $\mathrm{T}_{\mathrm{g}}$ (Table 1). During the curing process, we observed a slow loss of vacuum 143 potentially caused by the pressure increase associated with the heating. To maintain a 144 consistent vacuum, we resealed the oven in intervals of an increase of $7.5^{\circ} \mathrm{C}$, by reestablishing 145 the vacuum (-0.4 bar) and quickly purging the system with nitrogen. Upon completion of the 146 curing step, the SMP specimens were carefully removed from the molds and stored in a vacuum 147 desiccator (Bel-Art Lab) to ensure no moisture contamination occurred before subsequent 148 thermomechanical characterization experiments. 


\subsection{Characterization of the synthesized SMPs}

The mechanical properties of shape memory polymers vary according to temperature, especially in the range of their glass transition temperatures. To characterize these temperaturedependent mechanical properties with various polymer compositions, we conducted a series of thermomechanical tests, including the dynamic mechanical analysis (DMA), thermogravimetric analysis (TGA), differential scanning calorimetry (DSC), and uniaxial tensile tests considering failure and cyclic loading conditions, to pinpoint the glass transition temperature of the SMPs and to better understand their thermally-dependent mechanical behaviors.

\subsubsection{Dynamic mechanical analysis (DMA)}

Dynamic mechanical analysis (TA Q800) was used to measure the mechanical properties of synthesized SMPs. The SMP beam specimens were heated under a nitrogen atmosphere from $20^{\circ} \mathrm{C}$ to $120^{\circ} \mathrm{C}$ at a heating rate of $5^{\circ} \mathrm{C} / \mathrm{min}$ and in the tension mode with a cyclic frequency of 1 $\mathrm{Hz}$. DMA studies revealed the significant mechanical and thermal properties of the samples, such as storage modulus, loss modulus and glass transition temperature.

2.3.2 Thermogravimetric analysis (TGA) and differential scanning calorimetry (DSC)

Thermal analysis data were measured by both thermogravimetry (TA Q50, TA Instruments) and differential scanning calorimetry (TA Q20, TA Instruments). All measurements were performed under nitrogen environment. In brief, the thermal degradation behavior of the samples was recorded with heating from room temperature to $600^{\circ} \mathrm{C}$ at a rate of $10^{\circ} \mathrm{C} / \mathrm{min}$. An in-house MATLAB (MathWorks) program was used to determine the onset temperature of thermal degradation, which was used as reference for the ensuing DSC measurements. The program performed a linear regression on a section of each specimen's TGA curve below $T_{g}$, and another linear regression of the region on the TGA curve between $90 \%$ and $85 \%$ mass. The intersection of these two lines was determined to be the threshold of thermal stability. DSC measurements were carried out by: (1) heating from $20^{\circ} \mathrm{C}$ to $160^{\circ} \mathrm{C}$ at a rate of $5^{\circ} \mathrm{C} / \mathrm{min},(2)$ cooling to $20^{\circ} \mathrm{C}$ at $50^{\circ} \mathrm{C} / \mathrm{min}$, (3) maintaining for $3 \mathrm{~min}$ at $20^{\circ} \mathrm{C}$, and then (4) repeating the above procedures. DSC studies revealed the significant thermal properties of the samples, such as the glass transition temperature. All the DSC data presented in this study were from the second heating cycle.

2.4 Mechanical testing for the synthesized SMPs

Before performing tensile and cyclic testing on the SMP dog-bone specimens, the overflow region was removed to produce a clean finish on both sides of the specimen and eliminate 
180 imperfections. The samples were polished using a custom designed and 3D printed mount on a 181 rotary polishing machine (LaboPol-5, Struers). Once polished, the width and thickness of the 182 testing region were measured thrice each and averaged. Tensile failure testing was conducted 183 using a uniaxial tensile testing system (Instron 5969, Instron). Double-sided padded tape was 184 applied to both sides of each gripping region before mounting to prevent slippage during testing.

Failure testing was conducted at $10^{\circ} \mathrm{C}$ above the $T_{g}$ of each specimen in a temperature regulated environment on the Instron. The specimens were mounted in three steps. First, the base of the sample was clamped into the bottom set of grips and allowed to heat up to the temperature of the testing environment. Second, the top section was clamped into the top set of grips, and the distance between the two grips was measured with a caliper. After measuring the distance between the grips, the extension reading on the Instron was zeroed, and as the sample returned to testing temperature the grip positions were adjusted to keep the measured load as close to zero as possible. Finally, both sets of grips were tightened to make up for the relaxation of the SMP past its $T_{g}$. Once the sample reached testing temperature and the measured load was returned to zero, the extension measured by the Instron testing machine was added to the previously measured length and the extension was zeroed once again. This value was recorded as the initial length of the specimen. Upon starting the test, the specimens were subjected to a displacement of $2 \mathrm{~mm} / \mathrm{min}$ until failure. Five failure tests were completed per specimen, and the best three were selected for characterization purposes based on relative consistency of the elastic modulus and failure stress values.

The procedures for cyclic testing closely resembled those for failure testing. Another set of dog-bone specimens were tested at $10^{\circ} \mathrm{C}$ above $T_{g}$ and the same three step mounting procedures were exercised as previously mentioned. For the cyclic tests, each sample underwent three cycles of preconditioning at $25 \%$ of the failure strain as determined during failure testing. After the preconditioning step, the samples underwent ten loading and unloading cycles of the previously determined $50 \%$ failure strain. Both preconditioning and cycling steps were carried out at the same strain rate of $2 \mathrm{~mm} / \mathrm{min}$ as the failure tests.

2.5 Quantification of shape recovery capability

The shape recovery function of the synthesized SMPs was investigated by bending a straight beam sample at a $180^{\circ}$ angle, then measuring the time required for full recovery at various temperatures. We followed a method similar to the recovery tests employed by Lin et al. and Lan et al. (Lan et al., 2009; Lin and Chen, 1998a, b). In brief, the initial bend was achieved using 
212 a 3D printed mold. The beam was heated above its glass transition temperature, and then placed

213 into the mold where the specimen could cool and maintain its shape at the desired angle. To 214 measure the recovery time, a video camera was placed directly above a beaker of water on a 215 hot plate. The bent sample was held with forceps on a ring stand and swiftly lowered into the 216 heated water bath, where the SMP specimen was fully recovered. The video was analyzed frame 217 by frame to determine the elapsed time between any two specific angles of $45,90,135,165$, 218 and 180 degrees. This procedure was conducted using water baths at $T_{g}, T_{g}+5^{\circ} \mathrm{C}$, and $T_{g}+10^{\circ} \mathrm{C}$ 219 for each sample. Three repeated recovery tests were conducted at each of the above 220 temperature levels, resulting in a total of 9 recovery time measurements for each SMP 221 composition.

\section{3. Results}

223 3.1 DMA results

224 All SMP compositions showed a single steep transition in their shear storage modulus, each occurring at a different temperature threshold (Fig. 2a). A $\tan (\delta)$ plot (Fig. 2b) was used to determine the glass transition temperature of each SMP composition. These values were taken at the peak of the $\tan (\delta)$ plot and decreased monotonically from SMP1 to SMP12, ranging from $83.2^{\circ} \mathrm{C}$ to $32.3^{\circ} \mathrm{C}$ (Table 2). The storage moduli generally increased from SMP1 to SMP12; however, SMP10 exhibited exceptionally large values both above and below its glass transition temperature. Another factor which varied with the SMP composition was the change in the storage modulus from $T_{g}-5^{\circ} \mathrm{C}$ to $T_{g}+15^{\circ} \mathrm{C}$. With a few exceptions, the storage modulus of each specimen was reduced by a factor of $20-30$ times its value at $T_{g}-5^{\circ} \mathrm{C}$ when raised to $T_{g}+15^{\circ} \mathrm{C}$. Shear modulus values at both temperatures tended to be larger for specimens nearer to SMP12, but there was not a consistent increase from one composition to another. A notable outlier is the shear modulus of SMP10 at $T_{g}+15^{\circ} \mathrm{C}$, which is exceptionally large compared to the other compositions.

3.2 TGA results

The TGA testing results (Fig. 3) show two major slopes occurring near $300^{\circ} \mathrm{C}$ and $400^{\circ} \mathrm{C}$. The distinction between these two slopes becomes more pronounced for SMP compositions closer to SMP12 that contain high percentages of the TEA. Values for the onset of thermal degradation were determined for each composition with values, showing no consistent trend, ranging from $268.2^{\circ} \mathrm{C}$ to $284.7^{\circ} \mathrm{C}$ (Table 2). We determined the temperature at which each SMP composition degraded to $90 \%$ of its original weight. This value varied little between specimens, 
244 ranging from $275^{\circ} \mathrm{C}$ to $293^{\circ} \mathrm{C}$ (Table 2). Generally, this value increased from SMP1 to SMP12,

245 but with an appreciable variation between individual compositions. The temperature required to 246 degrade the SMPs to $50 \%$ weight varied more than the values for $90 \%$ degradation, ranging 247 from $356.6^{\circ} \mathrm{C}$ to $316.5^{\circ} \mathrm{C}$; however, these values showed a more uniform increase from SMP1 248 to SMP12 (Table 2).

$249 \quad 3.3 \mathrm{DSC}$ results

250 The results of the DSC tests were used as a secondary means of determining the $T_{g}$ of each 251 SMP composition (Fig. 4 and Table 2). To extract these values, we used the local minimum of 252 the resulting heat flow plots (Fig. 4), showing a monotonic decrease from SMP1 to SMP12. Such 253 a monotonic decrease is also reflected in the $T_{g}$ of the SMP compositions, ranging from $87^{\circ} \mathrm{C}$ to $25433^{\circ} \mathrm{C}$. These $T_{g}$ values from the DSC testing generally agree with the values determined using 255 the tan( $\delta$ ) plot in the DMA tests (Fig. 2). However, the $T_{g}$ values determined using DSC analysis 256 are consistently higher than those from DMA and $\tan (\delta)$ analysis, but the difference is small 257 enough to attribute to differences arising from the method of determination. The same difference 258 was observed in the analysis performed by Wilson et al. (Wilson et al., 2007).

2593.4 Uniaxial tensile testing results

260 Under uniaxial tensile failure tests, the SMPs exhibited a sharp decrease in the failure stress 261 and the failure strain from SMP1 to SMP3 and an increase in both failure stress and failure strain 262 from SMP3 to SMP12 (Fig. 5 and Table 3). The trends in the data are nonlinear, with large 263 increases near compositions SMP12 and SMP1 (Fig. 5). The maximum failure stress and strain 264 occur at SMP12 with values of $6.88 \mathrm{MPa} \pm 0.29 \mathrm{MPa}$ and $54.4 \% \pm 2.97 \%$, respectively. The 265 minimum stress and strain occur at SMP3 with values of $3.34 \mathrm{MPa} \pm 0.16 \mathrm{MPa}$ and $16.2 \% \pm$ $2660.72 \%$, respectively. For most of the specimens, we observed a decrease in both failure stress 267 and strain as the HPED content increased in the SMP composition.

268 As for the uniaxial tensile cyclic tests, the SMPs show a noticeable relaxation behavior under 269 cyclic tensile testing. This can be seen in the representative specimen (Fig. 6a). The relaxation 270 behavior is different depending on the specimen composition, and it generally decreases from 271 SMP1 to SMP12. However, this decrease is not uniform and requires more data collection before 272 any concrete trends relating to composition can be identified. Within individual specimens, the 273 relaxation behavior followed a regular pattern (Fig. 6a), exhibiting large but decreasing 274 relaxation during the first six cycles and then transitioning to uniform small relaxation during later 275 cycles. The maximum reduction observed at the end of the tenth cycle was $26.9 \% \pm 3.93 \%$ for 
276 SMP1, while the minimum was observed to be $1.15 \% \pm 0.04 \%$ for SMP9. The elastic moduli of

277 the SMPs were also affected by the cyclic loading, decreasing sharply during the first two cycles

278 but remaining nearly constant after the fourth (Fig. 6c). The elastic modulus also varies with the 279 SMP composition, with a gradual decrease from SMP1 to SMP12. SMP1 displayed the largest 280 elastic modulus with a value of $22.58 \mathrm{MPa} \pm 0.08 \mathrm{MPa}$, while SMP 12 displayed the smallest, 281 with a value of $13.14 \mathrm{MPa} \pm 0.31 \mathrm{MPa}$ (Table 3).

2823.5 Shape recovery capability

283 The SMPs showed a consistent temperature dependence in their shape recovery behavior, 284 an example of which is shown in Figure 7. Among individual specimens, the SMPs showed a 285 slower recovery response between the initiation of the test and the first $45^{\circ}$ of recovery, a fast, 286 linear response between $45^{\circ}$ and $135^{\circ}$, and a nonlinear deceleration as it approached a full $180^{\circ}$ 287 recovery. The results of the recovery tests indicated no significant trends in the recovery time 288 with relation to the SMP composition. There was a tendency for specimens with a high TEA 289 content (closer to SMP12) to recover faster than those with a high HPED content (closer to 290 SMP1). However, several SMP compositions fell outside of this trend that it cannot be 291 considered significant. Figure 8 shows a direct comparison of the recovery test results at $T_{g}+5^{\circ} \mathrm{C}$ 292 among 3 selected SMP compositions (SMP3, SMP7, and SMP11).

293 4. Discussion

294 4.1 Overall findings and relevance to endovascular embolization treatment for ICAs

295 The thermomechanical characterization of the aliphatic urethane SMPs provided a closer 296 look at the shift in material properties that occurs as each SMP reaches its $T_{g}$. The DMA results 297 showed a single sharp transition in the shear storage modulus for all compositions (Fig. 2a). We 298 observed that this transition occurs at different temperature levels depending on the SMP 299 composition, with higher glass transition temperatures corresponding to higher concentrations 300 of HPED. In this study, the glass transition temperature of the SMP specimen was determined 301 from these transitions with SMP compositions tested, ranging from $83.2^{\circ} \mathrm{C}$ to $32.3^{\circ} \mathrm{C}$. In the 302 context of implantable embolic devices, the SMP needs to possess a $T_{g}$ above body temperature 303 $\left(37^{\circ} \mathrm{C}\right)$ but below the threshold for tissue damage $\left(45^{\circ} \mathrm{C}\right)$ (Wang et al., 2014). If the $\mathrm{T}_{\mathrm{g}}$ is below 304 body temperature, then the implant would constantly exist in a malleable state and not hold any 305 one specific shape; however, at temperature levels greater than $45^{\circ} \mathrm{C}$, bodily tissues can begin 306 to take damage. This desired threshold falls within our observed $T_{g}$ values, suggesting that we 
307 can synthesize an aliphatic urethane SMP by employing the techniques detailed in this study, 308 which transitions at a temperature suitable for applications in the human body.

Moreover, uniaxial mechanical testing was conducted using the SMPs to determine their material strength and investigate how the strengths varied with composition. The failure test results suggested that higher values for both failure stress and strain occur in compositions with lower HPED contents, but the trend is nonlinear with significant variances at SMP3 (Fig. 5). Because of its irregular trends, this data will be difficult to use in a predictive manner, but it implies that there may be more complex changes associated with the SMP's composition than we previously expected. With a wider range of compositions and larger sample sizes for each composition, future studies could identify trends which could allow fabrications of SMP-based biomedical devices with specific material strengths.

Cyclic tensile testing was performed to investigate changes in the behavior of the SMP under repeated loading. The two major properties that we investigated were the elastic modulus and the peak stress value at 50\% failure strain (Table 3). GDC-based coils are designed to be left in the body for the remainder of a patient's lifetime, so it is important that the SMP materials used for this endovascular embolization application will not relax over time, resulting in the aneurysm recurrence. One behavior that the cyclic testing revealed was a noticeable reduction in the peak stress, with most of the reduction occurring during the first few cycles. This stress reduction reached a maximum value of $26.9 \% \pm 3.93 \%$ in SMP1 with respect to the first cycle, and the next highest values fell near the range of 8\%-9\% for SMPs 2-5. The relaxation behavior, which is not a desirable quality in the context of a permanent embolization device, was more pronounced for SMPs containing more HPED contents. The compositions containing large quantities of TEA contents exhibited less relaxation, reaching values as low as $1.15 \% \pm 0.04 \%$ for SMP9 and $1.92 \% \pm 1.36 \%$ for SMP11. However, due to a small sample size for our cyclic tests, we were not able to identify any quantitative relationship between the SMP composition and the stress relaxation behavior. In addition, the elastic modulus also varied with cyclic loading, but only during the first few cycles of the test. The elastic modulus values decreased sharply during the first cycle, but quickly reached a constant value around the third or fourth cycle (Fig. 6a). Even though the changes in elastic modulus are small, it is in our interest to minimize any changes in material properties once the SMP is introduced into the body. Since we were able to observe both the stress relaxation and elastic modulus approaching a stable point in the latter cycles of our tests, we expect that it would be necessary to design the embolization devices to 
339 undergo pre-cycling before implantation, minimizing the effects of initial relaxation when the 340 device is administered.

341 Another important factor in designing an embolic device made from SMPs is the shape 342 recovery behavior which occurs when the polymer transitions from a deformed state to its un343 stressed state. The recovery tests conducted in this study focused on the time required for the 344 SMP to recover its shape. For endovascular embolization of ICAs, short recovery time of the 345 SMP-based device is an important design criterion to avoid the prolonged heating of body tissues 346 during device deployment. We showed the recovery behavior of the SMPs to be temperature 347 dependent, speeding up as temperatures increased past the $T_{g}$. At $T_{g}+10^{\circ} \mathrm{C}$, with no composition 348 taking more than 10.3 seconds to fully recover from a $180^{\circ}$ bend. There was noticeable variation 349 among different compositions, and it is very likely that a more complex relationship exists 350 between the SMP composition and the polymer's recovery behavior. Such relationships are 351 beyond the scope of this study and could be further investigated in the future. The quick recovery 352 time displayed by all compositions is promising for our continued efforts toward the development 353 of an improved aneurysm embolization device. If a device made using this SMP material could 354 be intravenously moved to its target location and then reconfigured in a matter of seconds, it 355 would have the ability to improve a great number of medical procedures.

$356 \quad 4.2$ Study limitations and Future Work

357 This study featured a comprehensive set of thermomechanical characterization 358 experiments, and as a result had a plethora of limiting factors that could have contributed to the 359 variations in our data. The most prominent of these limitations is a relative smaller sample size 360 for our cyclic tensile test, failure test, and recovery test. Two sets of data for each composition 361 were taken during cyclic testing, and three were taken for each composition during failure testing. 362 For the recovery tests, three trials were performed for each temperature point for each 363 composition. The focus of this study was to conduct a broad analysis of aliphatic urethane shape 364 memory polymers with varying SMP compositions. Consequently, we sacrificed the data 365 statistical meaningfulness that comes with a large sample size to instead survey a wide range 366 of compositions for trends and patterns. As future extensions based on the results of this general 367 characterization, we plan to focus on a single composition range and collect more thorough 368 measurements to quantitatively define the trends observed in this study.

Within the uniaxial failure and cyclic tensile tests, there are several factors that could have affected our results. The samples that we used were all synthesized at the beginning of our 
371 testing period, and so it is possible that the ones that were tested later in the study could have 372 changed over time as they were stored (e.g., absorbing moisture). This could be remedied by 373 testing each composition at the same amount of time after synthesis to ensure age is constant. 374 The sample were attached to the uniaxial tester using double sided tape to avoid slippage. 375 Deformations in this tape layer or slight slippages on the adhesive could have resulted in skewed 376 results. However, since all samples were tested the same way, the error due to this mounting 377 method should be consistent. Small imperfections in the samples, such as bubbles or 378 heterogeneity in the monomer mixtures, could have also resulted in differences between 379 samples in a composition. These errors can be reduced as the synthesis procedure is perfected, 380 and researchers should be careful to select only pristine samples for testing.

381 The recovery tests we conducted had many aspects that can be improved upon. Our 382 measurement method relied on visual inspection to determine the angular position of the sample 383 and the frame at which the position of interest was reached. From the frame analysis, we 384 determined time elapsed. This entire measurement method is subject to human error in multiple 385 places, which is difficult to account for. It would be beneficial to determine a more exact way to 386 measure recovery. Some samples did not return completely to a straight angle, and others began their deformation at an angle other than $180^{\circ}$. While the recovery times were still useful for our analyses, a study looking to definitively quantify the recovery response of these materials would need to better define the start and end conditions for the tests.

It is essential that endovascular devices are visible under $\mathrm{X}$-ray based fluoroscopy so that physicians can pinpoint their location and orientation during device deployment. Urethane-based shape memory polymers are typically invisible to radiographic imaging techniques, and, therefore, the addition of radio-opaque additives to the polymer composition is necessary for their use in the endovascular embolization applications. For instance, Wong et al. created composite blends of poly (DL-lactide-co-glycolide) (PLGA) with both tantalum and bismuth (III) oxychloride, which appeared clearly in radiographic images whereas the shape memory effect can be maintained (Wong et al., 2016). While not investigated in this study, we plan to examine different radio-opaque additives in our aliphatic urethane SMP and determine any resulting changes in the SMP material properties.

The use of heat as an activation mechanism of SMP shape recovery poses many challenges, especially in an area as sensitive as the brain artery vessel tissues. Although our study has identified a range of SMP compositions that transition at biologically safe temperatures, 
403 the challenge of delivering the thermal stimulus remains. There is a wealth of literature 404 discussing diverse activation techniques, many of which are based on the indirect delivery of 405 thermal energy to the material. These methods include, but are not limited to, Joule heating with 406 the addition of conductive inclusions, optical heating achieved using wavelength specific dyes 407 and a matching laser light source, and magnetic stimulation of nanoparticles (Huang et al., 2013; 408 Small et al., 2007). Another activation technique uses chemical interactions to lower the $T_{g}$ of 409 the SMP below ambient temperature, triggering the shape memory effect. This effect occurs 410 slowly in polyurethane SMPs, and quickly in hydrogels, when the materials are exposed to water 411 (Huang et al., 2005; Lu and Du, 2014; Salvekar et al., 2017; Wong et al., 2016). As part of our 412 future extensions, we plan to test a wide range of activation techniques to determine the method 413 most suitable for the deployment of an endovascular embolization device. Because of the slow 414 reaction to water that has been observed in polyurethane SMPs from the research of Huang et 415 al. and Lu et al., we also intend to study the long-term effects of moisture on our embolic devices 416 after deployment (Huang et al., 2005; Lu et al., 2014).

$417 \quad 4.3$ Conclusion

418 This study aimed to characterize a range of compositions of aliphatic urethane shape 419 memory polymers for their potential use in the treatment of intracranial aneurysms. In specific, 420 we developed a detailed synthesis procedure for the SMPs to provide our study with a variety of 421 compositions and inform future studies seeking to utilize the same material. We have 422 investigated the thermomechanical properties including the glass transition temperature and 423 thermal stability of each composition, and we have also found that compositions between SMP9 424 and SMP11 possess transition temperatures between body temperature and the threshold of 425 tissue damage. This is the optimal $\mathrm{T}_{\mathrm{g}}$ range for allowing the polymers to remain functionable 426 within the body without causing any tissue damage due to the heating associated with shape 427 change triggering. We have also found that within our desired operating temperatures, all SMP 428 compositions are thermally stable regarding the endovascular embolization procedure. We have 429 also characterized the mechanical properties of the SMPs and identified decreases in both 430 maximum stress and elastic modulus with cyclic loading. Our results showed that in SMPs closer 431 to SMP12, these decreases were not as prominent. Since any changes in material properties 432 during the lifetime of an implanted device are detrimental, the SMP compositions near SMP12 433 are more desirable in the context of endovascular embolization treatment for ICAs. Finally, we 434 have tested the recovery time of each polymer and showed that all the SMP compositions are 
435 capable of recovering from a $180^{\circ}$ bend within 10.3 seconds. Using knowledge from the broad 436 characterization performed in this study, we have identified a range of compositions between 437 SMP9 and SMP11 that most accurately meet our criteria with their great potential for the 438 individualized treatment of intracranial aneurysms, and they will be analyzed further in more 439 detail as a part of future studies. 


\section{Acknowledgments}

Funding support from the Oklahoma Shared Clinical and Translational Resources (OSCTR) Pilot Project Program (NIGMS U54GM104938) and the Oklahoma Center for the Advancement of Science \& Technology (OCAST) Health Research Program is gratefully acknowledged. CHL was in part supported by the institutional start-up funds from the School of Aerospace and Mechanical Engineering (AME) and the research funding through the SEED Funding for Interdisciplinary Research from the Gallogly College of Engineering and the Faculty Investment Program from the Research Council at the University of Oklahoma (OU). RK and DL were supported by the Mentored Research Fellowship from the Office of Undergraduate Research at OU.

\section{Conflicts of Interest}

None of the authors have a conflict of interest with the present work. 
Tables

Table 1. Percent monomer content, monomer-mixture stirring time, and the curing heating rate for all the twelve SMP compositions.

\begin{tabular}{|l|c|c|c|c|c|}
\hline & \multicolumn{3}{|c|}{ Monomer Content (\%) } & \multirow{2}{*}{$\begin{array}{c}\text { Stirring Time } \\
\text { (seconds) }\end{array}$} & $\begin{array}{c}\text { Heating Rate } \\
\left({ }^{\circ} \mathrm{C} / \text { hour }\right)\end{array}$ \\
\cline { 2 - 3 } & HDI & HPED & TEA & 150 & $30.0^{*}$ \\
\hline SMP1 & 53.5 & 46.5 & 0.0 & 170 & 29.6 \\
\hline SMP2 & 53.9 & 44.5 & 1.6 & 200 & 29.2 \\
\hline SMP3 & 54.3 & 42.5 & 3.2 & 225 & 26.4 \\
\hline SMP4 & 55.1 & 38.4 & 6.5 & 240 & 25.2 \\
\hline SMP5 & 56.0 & 34.1 & 9.9 & 255 & 23.6 \\
\hline SMP6 & 56.9 & 29.7 & 13.4 & 270 & 21.1 \\
\hline SMP7 & 57.8 & 25.1 & 17.1 & 285 & 18.5 \\
\hline SMP8 & 58.8 & 20.4 & 20.8 & 310 & 15.9 \\
\hline SMP9 & 59.7 & 15.6 & 24.7 & 330 & 12.5 \\
\hline SMP10 & 60.7 & 10.6 & 28.7 & 350 & 9.6 \\
\hline SMP11 & 61.8 & 5.4 & 32.8 & 445 & 8.5 \\
\hline SMP12 & 62.3 & 2.7 & 35.0 & & \\
\hline
\end{tabular}

*Suggested same heating rate for SMP curing in Wilson et al. (Wilson et al., 2007).

Table 2. Glass transition temperature $\left(T_{g}\right)$ and storage modulus from the DMA tests (c.f. Fig. 2), $T_{g}$ from the DSC tests (c.f. Fig. 4), and the temperature levels associated with $90 \%$ and $50 \%$ remaining weights of the SMPs from the TGA tests (c.f. Fig. 3).

\begin{tabular}{|l|c|c|c|c|c|c|c|}
\hline & \multicolumn{3}{|c|}{ DMA } & DSC & \multicolumn{3}{c|}{ TGA } \\
\cline { 2 - 8 } & $\begin{array}{c}\mathrm{T}_{\mathrm{g}} \\
\left({ }^{\circ} \mathrm{C}\right)\end{array}$ & $\begin{array}{c}\text { Storage } \\
\text { modulus } \\
\text { at } \mathrm{T}_{\mathrm{g}}-5^{\circ} \mathrm{C} \\
(\mathrm{MPa})\end{array}$ & $\begin{array}{c}\text { Storage } \\
\text { modulus } \\
\text { at } \\
\mathrm{Tg}+15^{\circ} \mathrm{C} \\
(\mathrm{MPa})\end{array}$ & $\begin{array}{c}\text { Temperature } \\
\mathrm{T}_{\mathrm{g}}\end{array}$ & $\begin{array}{c}\left.{ }^{\circ} \mathrm{C}\right) \\
\text { associated } \\
\text { with the onset } \\
\text { of thermal } \\
\text { degradation }\end{array}$ & $\begin{array}{c}\text { Temperature } \\
\left({ }^{\circ} \mathrm{C}\right) \\
\text { associated } \\
\text { with 90\% } \\
\text { remaining } \\
\text { weight }\end{array}$ & $\begin{array}{c}\text { Temperature } \\
\left({ }^{\circ} \mathrm{C}\right) \\
\text { associated } \\
\text { with } 50 \% \\
\text { remaining } \\
\text { weight }\end{array}$ \\
\hline SMP1 & 83.2 & 403.3 & 13.3 & 87 & 276.6 & 289.5 & 356.6 \\
\hline SMP2 & 79.5 & 442.0 & 13.4 & 83 & 278.2 & 288.7 & 353.6 \\
\hline SMP3 & 72.6 & 459.4 & 15.7 & 76 & 276.6 & 286.3 & 351.4 \\
\hline SMP4 & 65.7 & 529.6 & 19.3 & 73 & 284.7 & 293.5 & 351.0 \\
\hline SMP5 & 61.1 & 563.4 & 22.4 & 67 & 277.5 & 287.1 & 342.8 \\
\hline SMP6 & 55.5 & 589.8 & 26.8 & 63 & 276.8 & 285.5 & 341.2 \\
\hline SMP7 & 52.5 & 649.9 & 23.7 & 56 & 275.9 & 284.5 & 338.1 \\
\hline SMP8 & 47.5 & 759.4 & 46.0 & 53 & 278.4 & 285.8 & 333.8 \\
\hline SMP9 & 42.6 & 706.4 & 24.6 & 45 & 276.7 & 284.8 & 331.0 \\
\hline SMP10 & 37.2 & 882.7 & 142.7 & 39 & 270.8 & 279.2 & 321.2 \\
\hline SMP11 & 33.9 & 830.9 & 43.8 & 34 & 268.2 & 275.5 & 316.5 \\
\hline SMP12 & 32.3 & 867.7 & 23.9 & 33 & 272.8 & 279.3 & 318.7 \\
\hline
\end{tabular}


Table 3. Failure stresses and failure strains from the uniaxial tensile failure testing (c.f. Fig. 5) and the stress reductions and the calculated elastic modulus from the uniaxial cyclic tensile testing (c.f.

Fig. 6) for all the twelve SMP compositions. Tensile tests conducted at $\mathrm{Tg}+10^{\circ} \mathrm{C}$.

\begin{tabular}{|c|c|c|c|c|c|}
\hline & \multicolumn{2}{|c|}{ Uniaxial Tensile Failure Test } & \multicolumn{3}{|c|}{ Uniaxial Cyclic Tensile Test } \\
\hline & \multirow{2}{*}{$\begin{array}{l}\text { Failure stress } \\
\qquad(\mathrm{MPa})\end{array}$} & \multirow[b]{2}{*}{$\begin{array}{l}\text { Failure strain } \\
\qquad(\%)\end{array}$} & \multicolumn{2}{|c|}{ Cumulative stress reduction (\%) } & \multirow{2}{*}{$\begin{array}{c}\text { Elastic modulus at the } \\
10^{\text {th }} \text { cycle (MPa) }\end{array}$} \\
\hline & & & $\begin{array}{l}2^{\text {nd }} \text { cycle w.r.t. } \\
1^{\text {st }} \text { cycle }\end{array}$ & $\begin{array}{c}10^{\text {th }} \text { cycle w.r.t. } \\
1^{\text {st }} \text { cycle }\end{array}$ & \\
\hline SMP1 & $4.68 \pm 0.23$ & $26.5 \pm 2.11$ & $7.66 \pm 0.42$ & $26.9 \pm 3.93$ & $22.58 \pm 0.08$ \\
\hline SMP2 & $3.78 \pm 0.21$ & $22.1 \pm 1.24$ & $3.36 \pm 0.98$ & $7.88 \pm 2.16$ & $20.74 \pm 0.52$ \\
\hline SMP3 & $3.34 \pm 0.16$ & $16.2 \pm 0.72$ & $1.83 \pm 0.59$ & $9.08 \pm 4.58$ & $18.97 \pm 0.33$ \\
\hline SMP4 & $3.84 \pm 0.07$ & $20.9 \pm 0.32$ & $3.14 \pm 0.03$ & $9.06 \pm 0.54$ & $19.84 \pm 0.04$ \\
\hline SMP5 & $3.74 \pm 0.22$ & $25.3 \pm 0.76$ & $3.30 \pm 0.62$ & $8.39 \pm 1.66$ & $18.80 \pm 0.82$ \\
\hline SMP6 & $4.11 \pm 0.17$ & $28.7 \pm 0.83$ & $2.79 \pm 0.03$ & $6.64 \pm 0.49$ & $20.39 \pm 1.48$ \\
\hline SMP7 & $4.29 \pm 0.11$ & $30.9 \pm 3.14$ & $2.28 \pm 0.29$ & $5.68 \pm 0.37$ & $18.50 \pm 0.18$ \\
\hline SMP8 & $4.45 \pm 0.43$ & $31.6 \pm 2.44$ & $2.26 \pm 0.25$ & $6.70 \pm 0.24$ & $19.04 \pm 0.77$ \\
\hline SMP9 & $4.76 \pm 0.28$ & $32.7 \pm 0.58$ & $0.41 \pm 0.12$ & $1.15 \pm 0.04$ & $18.34 \pm 2.12$ \\
\hline SMP10 & $4.74 \pm 0.14$ & $36.5 \pm 2.14$ & $0.51 \pm 0.09$ & $7.42 \pm 0.03$ & $16.32 \pm 0.52$ \\
\hline SMP11 & $5.25 \pm 0.55$ & $43.2 \pm 6.29$ & $0.80 \pm 0.47$ & $1.92 \pm 1.36$ & $15.26 \pm 0.25$ \\
\hline SMP12 & $6.88 \pm 0.29$ & $54.4 \pm 2.97$ & $0.93 \pm 0.06$ & $3.34 \pm 0.85$ & $13.14 \pm 0.31$ \\
\hline
\end{tabular}




\section{Figure Captions}

Figure 1 - (a) Top-view schematic of the in-house equipment used in the shape memory polymer synthesis. (b) An illustration of the synthesis procedure showing specifically (i) the measurement of each monomer, (ii) the mixture of monomers to form the polymer, (iii) the deposition of the mixture into previously cast molds, and (iv) the curing of the mixture in a vacuum oven.

Figure 2 - (a) Shear storage modulus of all the twelve SMP compositions as directly measured from the DMA tests, and (b) tan $(\delta)$ curves as derived from the DMA testing results for determining the $T_{g}$ of each SMP composition.

Figure 3 - TGA results showing the decomposition of the SMP with increasing temperature.

Figure 4 - DSC results used for determinations of the $T_{g}$ for each SMP composition.

Figure 5 - Mean \pm SEM of the failure stress (blue filled squares) and failure strain (red filled circles) for all the twelve SMP compositions $(n=2)$ under uniaxial tension testing $\left(T_{g}+10^{\circ} \mathrm{C}\right)$.

Figure 6 - Representative cyclic mechanical testing results (SMP3) when tested at $50 \%$ of the observed failure strain $\left(\mathrm{T}_{\mathrm{g}}+10^{\circ} \mathrm{C}\right)$ showing: (a) the relaxation trend in the peak stress with an increasing number of cycles, (b) the increase in the cumulative stress reduction and (c) the convergence of the elastic modulus with an increasing number of cycles.

Figure 7 - Mean \pm SEM of the recovery testing time for a representative SMP composition (SMP3, $n=3$ ) showing the consistent trend of reduced recovery time with an increased temperature.

Figure 8 - Representative experimental photos of the recovery testing for three representative SMP compositions (SMP3, SMP7, and SMP11) at defined time increments ( $t=0 \mathrm{sec}, \mathrm{t}=2 \mathrm{sec}, \mathrm{t}=4 \mathrm{sec}$, and $t=6 \mathrm{sec}$ ), showing the observed trend of a decreasing recovery time with an increasing TEA content. 


\section{References}

Bederson, J.B., Connolly, E.S., Batjer, H.H., Dacey, R.G., Dion, J.E., Diringer, M.N., Duldner, J.E., Harbaugh, R.E., Patel, A.B., Rosenwasser, R.H., 2009. Guidelines for the management of aneurysmal subarachnoid hemorrhage a statement for healthcare professionals from a special Writing Group of the Stroke Council, American Heart Association. Stroke 40, 994-1025.

Campi, A., Ramzi, N., Molyneux, A.J., Summers, P.E., Kerr, R.S., Sneade, M., Yarnold, J.A., Rischmiller, J., Byrne, J.V., 2007. Retreatment of ruptured cerebral aneurysms in patients randomized by coiling or clipping in the International Subarachnoid Aneurysm Trial (ISAT). Stroke 38, 1538-1544.

Connolly, E.S., Rabinstein, A.A., Carhuapoma, J.R., Derdeyn, C.P., Dion, J., Higashida, R.T., Hoh, B.L., Kirkness, C.J., Naidech, A.M., Ogilvy, C.S., 2012. Guidelines for the management of aneurysmal subarachnoid hemorrhage: a guideline for healthcare professionals from the American Heart Association/American Stroke Association. Stroke 43, 1711-1737.

Guglielmi, G., Viñuela, F., Dion, J., Duckwiler, G., 1991. Electrothrombosis of saccular aneurysms via endovascular approach: part 2: preliminary clinical experience. J. Neurosurg. 75, 8-14.

Gunes, I.S., Cao, F., Jana, S.C., 2008. Effect of thermal expansion on shape memory behavior of polyurethane and its nanocomposites. Journal of Polymer Science Part B: Polymer Physics 46, 1437-1449.

Hope, J.A., Byrne, J.V., Molyneux, A.J., 1999. Factors influencing successful angiographic occlusion of aneurysms treated by coil embolization. Am. J. Neuroradiol. 20, 391-399.

Huang, H.-Y.S., Balhouse, B.N., Huang, S., 2012. Application of simple biomechanical and biochemical tests to heart valve leaflets: implications for heart valve characterization and tissue engineering. Proceedings of the Institution of Mechanical Engineers, Part $\mathrm{H}$ : Journal of Engineering in Medicine 226, 868-876.

Huang, W., Yang, B., An, L., Li, C., Chan, Y., 2005. Water-driven programmable polyurethane shape memory polymer: demonstration and mechanism. Appl. Phys. Lett. 86, 114105.

Huang, W.M., Song, C., Fu, Y.Q., Wang, C.C., Zhao, Y., Purnawali, H., Lu, H., Tang, C., Ding, Z., Zhang, J., 2013. Shaping tissue with shape memory materials. Adv. Drug Del. Rev. 65, 515-535.

King Jr, J.T., 1997. Epidemiology of aneurysmal subarachnoid hemorrhage. Neuroimaging Clin. N. Am. 7,659.

Lan, X., Liu, Y., Lv, H., Wang, X., Leng, J., Du, S., 2009. Fiber reinforced shape-memory polymer composite and its application in a deployable hinge. Smart Materials and Structures 18, 024002.

Lantigua, H., Ortega-Gutierrez, S., Schmidt, J.M., Lee, K., Badjatia, N., Agarwal, S., Claassen, J., Connolly, E.S., Mayer, S.A., 2015. Subarachnoid hemorrhage: who dies, and why? Critical care 19, 309.

Lendlein, A., Langer, R., 2002. Biodegradable, elastic shape-memory polymers for potential biomedical applications. Science 296, 1673-1676.

Lin, J., Chen, L., 1998a. Study on shape - memory behavior of polyether - based polyurethanes. I. Influence of the hard - segment content. J. Appl. Polym. Sci. 69, 1563-1574.

Lin, J., Chen, L., 1998b. Study on shape - memory behavior of polyether - based polyurethanes. II. Influence of soft - segment molecular weight. J. Appl. Polym. Sci. 69, 1575-1586.

Lu, H., Du, S., 2014. A phenomenological thermodynamic model for the chemo-responsive shape memory effect in polymers based on Flory-Huggins solution theory. Polymer Chemistry 5, 11551162.

Lu, H., Huang, W.M., Fu, Y.Q., Leng, J., 2014. Quantitative separation of the influence of hydrogen bonding of ethanol/water mixture on the shape recovery behavior of polyurethane shape memory polymer. Smart Materials and Structures 23, 125041.

Maitland, D.J., Metzger, M.F., Schumann, D., Lee, A., Wilson, T.S., 2002. Photothermal properties of shape memory polymer micro - actuators for treating stroke. Lasers Surg. Med. 30, 1-11. 
Molyneux, A., Group, I.S.A.T.C., 2002. International Subarachnoid Aneurysm Trial (ISAT) of neurosurgical clipping versus endovascular coiling in 2143 patients with ruptured intracranial aneurysms: a randomised trial. Lancet 360, 1267-1274.

Molyneux, A.J., Kerr, R.S., Birks, J., Ramzi, N., Yarnold, J., Sneade, M., Rischmiller, J., collaborators, I., 2009. Risk of recurrent subarachnoid haemorrhage, death, or dependence and standardised mortality ratios after clipping or coiling of an intracranial aneurysm in the International Subarachnoid Aneurysm Trial (ISAT): long-term follow-up. The Lancet Neurology 8, 427-433.

Molyneux, A.J., Kerr, R.S., Yu, L.-M., Clarke, M., Sneade, M., Yarnold, J.A., Sandercock, P., Group, I.S.A.T.C., 2005. International subarachnoid aneurysm trial (ISAT) of neurosurgical clipping versus endovascular coiling in 2143 patients with ruptured intracranial aneurysms: a randomised comparison of effects on survival, dependency, seizures, rebleeding, subgroups, and aneurysm occlusion. The Lancet 366, 809-817.

Naval, N.S., Chang, T., Caserta, F., Kowalski, R.G., Carhuapoma, J.R., Tamargo, R.J., 2012. Impact of pattern of admission on outcomes after aneurysmal subarachnoid hemorrhage. J. Crit. Care 27, 532. e531-532. e537.

Raymond, J., Guilbert, F., Weill, A., Georganos, S.A., Juravsky, L., Lambert, A., Lamoureux, J., Chagnon, M., Roy, D., 2003. Long-term angiographic recurrences after selective endovascular treatment of aneurysms with detachable coils. Stroke 34, 1398-1403.

Rinkel, G.J., Djibuti, M., Algra, A., Van Gijn, J., 1998. Prevalence and risk of rupture of intracranial aneurysms. Stroke 29, 251-256.

Sacco, R.L., Wolf, P.A., Bharucha, N.E., Meeks, S.L., Kannel, W.B., Charette, L.J., McNamara, P.M., Palmer, E.P., D'Agostino, R., 1984. Subarachnoid and intracerebral hemorrhage Natural history, prognosis, and precursive factors in the Framingham Study. Neurology 34, 847-847.

Salvekar, A.V., Huang, W.M., Xiao, R., Wong, Y.S., Venkatraman, S.S., Tay, K.H., Shen, Z.X., 2017. Water-responsive shape recovery induced buckling in biodegradable photo-cross-linked poly (ethylene glycol)(PEG) hydrogel. Acc. Chem. Res. 50, 141-150.

Schievink, W.I., 1997. Intracranial aneurysms. New Engl. J. Med. 336, 28-40.

Small, W., Buckley, P.R., Wilson, T.S., Benett, W.J., Hartman, J., Saloner, D., Maitland, D.J., 2007. Shape memory polymer stent with expandable foam: a new concept for endovascular embolization of fusiform aneurysms. IEEE Trans. Biomed. Eng. 54, 1157-1160.

Taha, M.M., Nakahara, I., Higashi, T., Iwamuro, Y., Iwaasa, M., Watanabe, Y., Tsunetoshi, K., Munemitsu, T., 2006. Endovascular embolization vs surgical clipping in treatment of cerebral aneurysms: morbidity and mortality with short-term outcome. Surg. Neurol. 66, 277-284.

Tateshima, S., Murayama, Y., Gobin, Y.P., Duckwiler, G.R., Guglielmi, G., Viñuela, F., 2000. Endovascular treatment of basilar tip aneurysms using Guglielmi detachable coils: anatomic and clinical outcomes in 73 patients from a single institution. Neurosurgery 47, 1332-1342.

Vallée, J.-N., Aymard, A., Vicaut, E., Reis, M., Merland, J.-J., 2003. Endovascular Treatment of Basilar Tip Aneurysms With Guglielmi Detachable Coils: Predictors of Immediate and Long-term Results with Multivariate Analysis-6-year Experience. Radiology 226, 867-879.

Wache, H., Tartakowska, D., Hentrich, A., Wagner, M., 2003. Development of a polymer stent with shape memory effect as a drug delivery system. J. Mater. Sci. Mater. Med. 14, 109-112.

Wang, H., Wang, B., Normoyle, K.P., Jackson, K., Spitler, K., Sharrock, M.F., Miller, C.M., Best, C., Llano, D., Du, R., 2014. Brain temperature and its fundamental properties: a review for clinical neuroscientists. Front. Neurosci. 8, 307.

Wardlaw, J., White, P., 2000. The detection and management of unruptured intracranial aneurysms. Brain 123, 205-221.

Wehman, J.C., Hanel, R.A., Levy, E.I., Hopkins, L.N., 2006. Giant cerebral aneurysms: endovascular challenges. Neurosurgery 59, S3-125.

Wilson, T., Bearinger, J., Herberg, J., Marion, J., Wright, W., Evans, C., Maitland, D., 2007. Shape memory polymers based on uniform aliphatic urethane networks. J. Appl. Polym. Sci. 106, 540-551. 
Wong, Y.S., Salvekar, A.V., Da Zhuang, K., Liu, H., Birch, W.R., Tay, K.H., Huang, W.M., Venkatraman, S.S., 2016. Bioabsorbable radiopaque water-responsive shape memory embolization plug for temporary vascular occlusion. Biomaterials 102, 98-106.

Xu, J., Shi, W., Pang, W., 2006. Synthesis and shape memory effects of Si-O-Si cross-linked hybrid polyurethanes. Polymer 47, 457-465. 
Figure 1

(a)

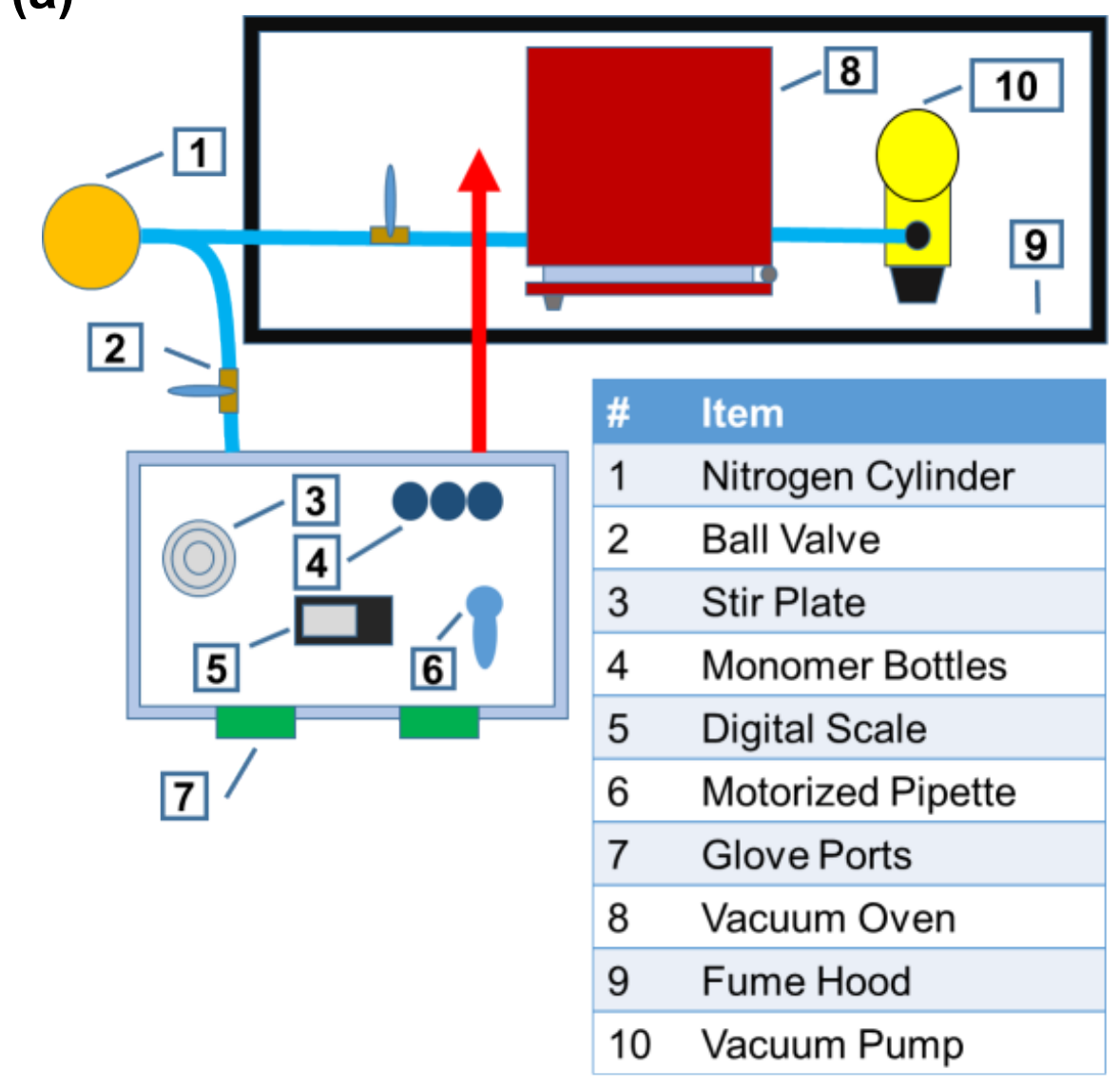

(b)

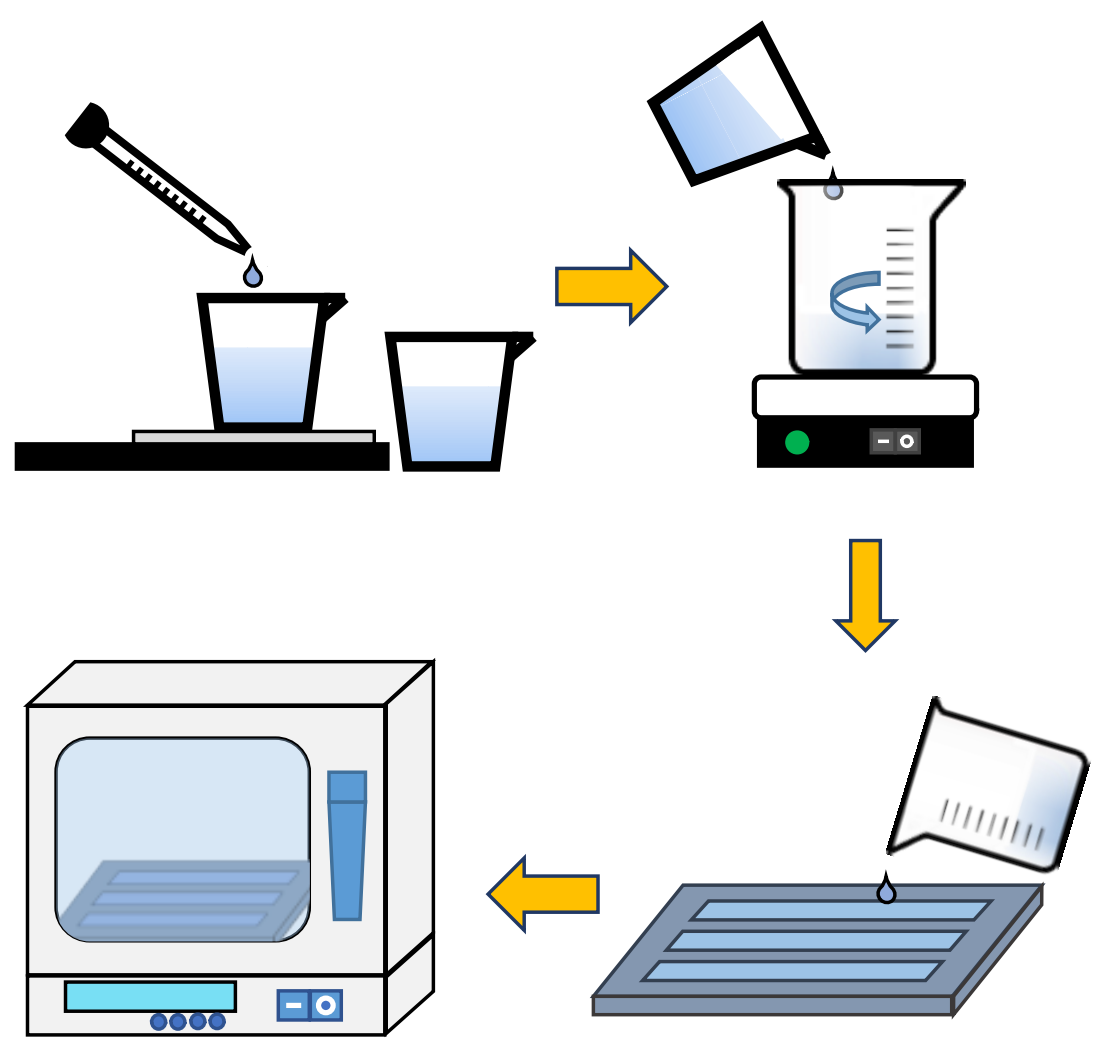


Figure 3

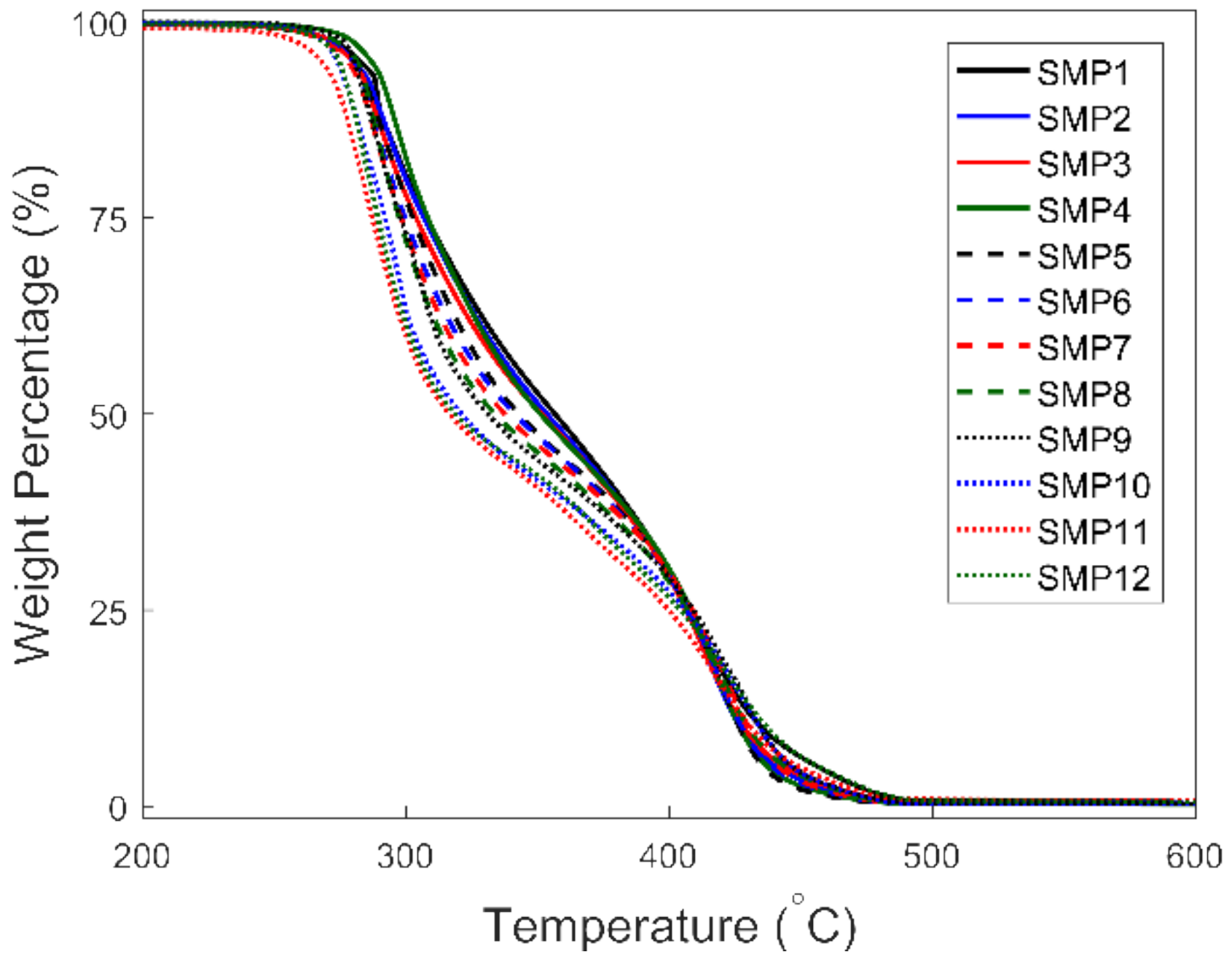


Figure 4

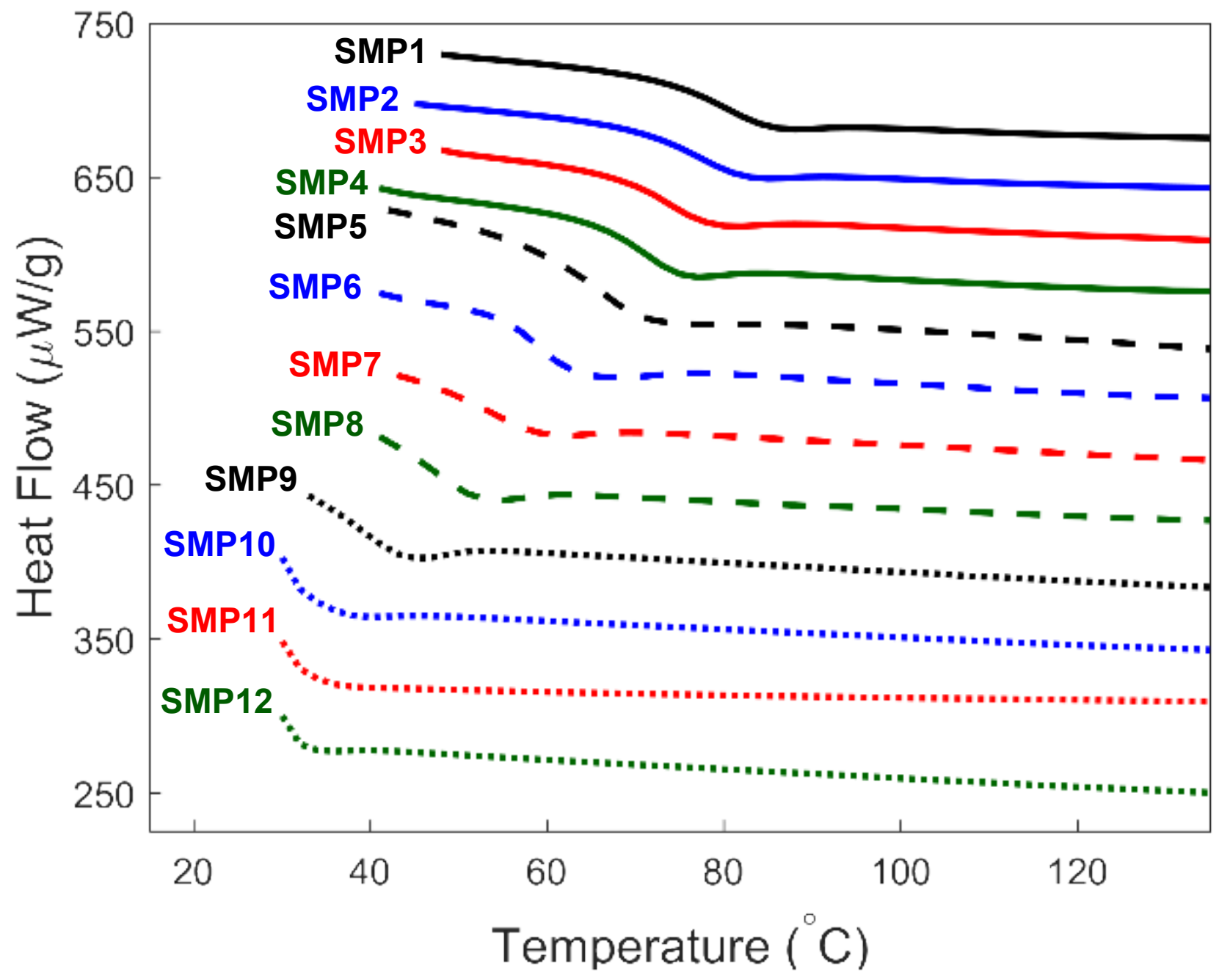


Figure 5

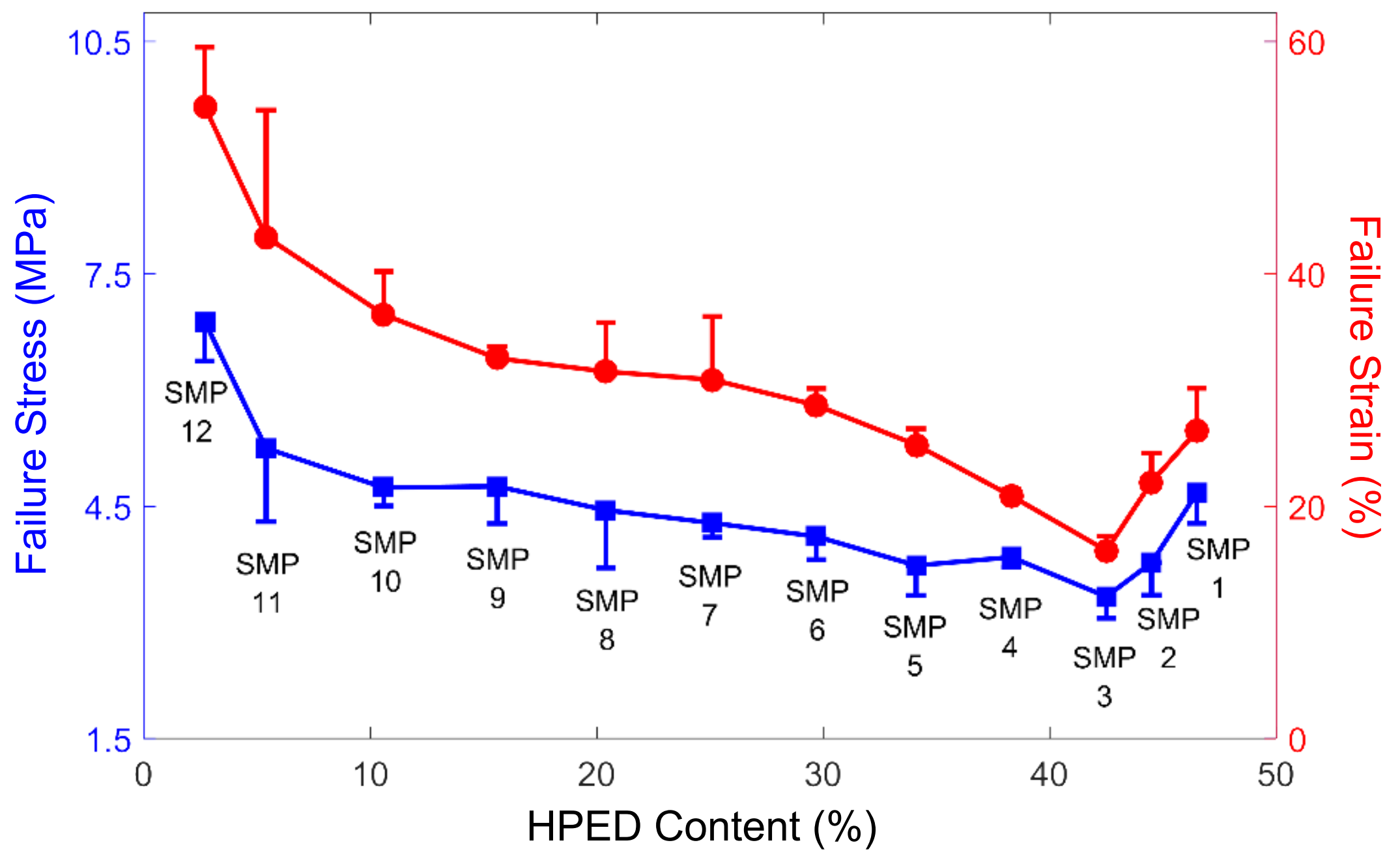


(b)

(a)

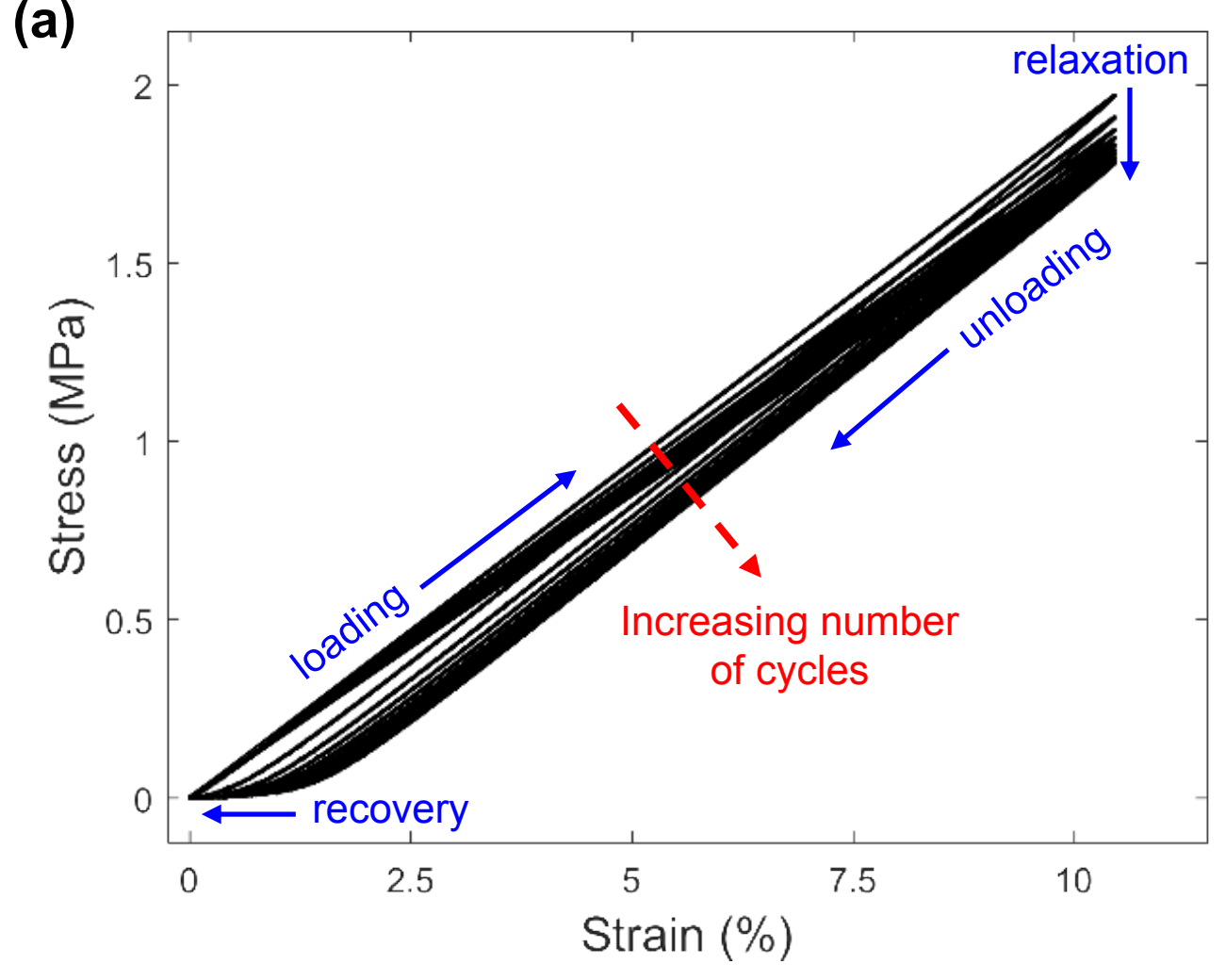

(c)
Figure 6
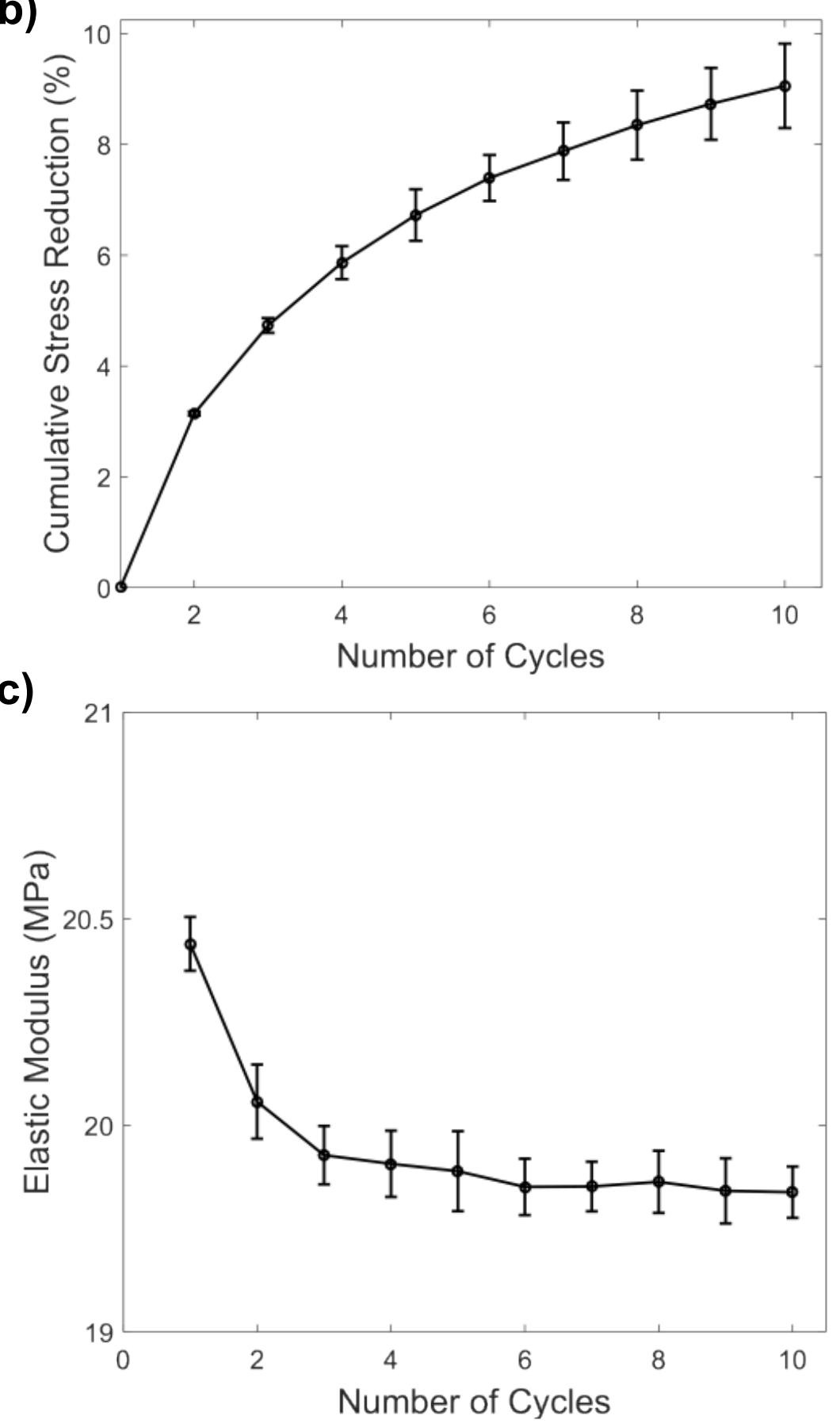
Figure 7

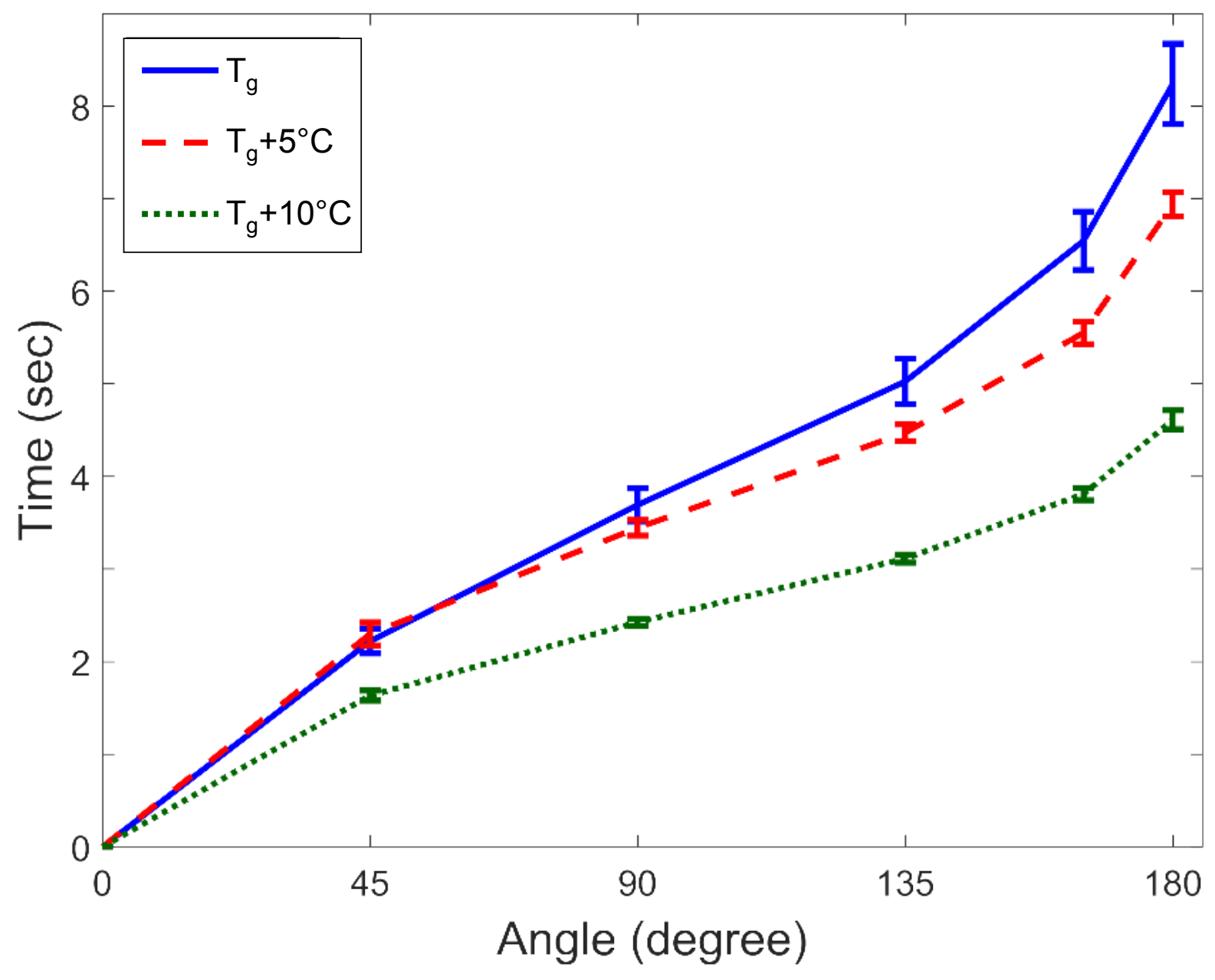


Figure 8
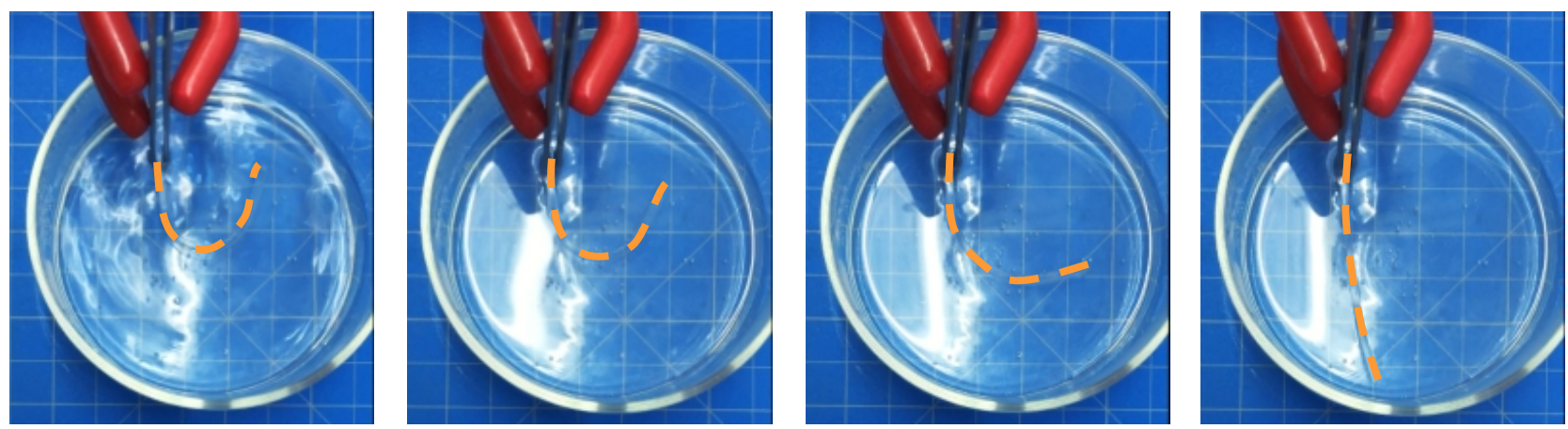

SMP3
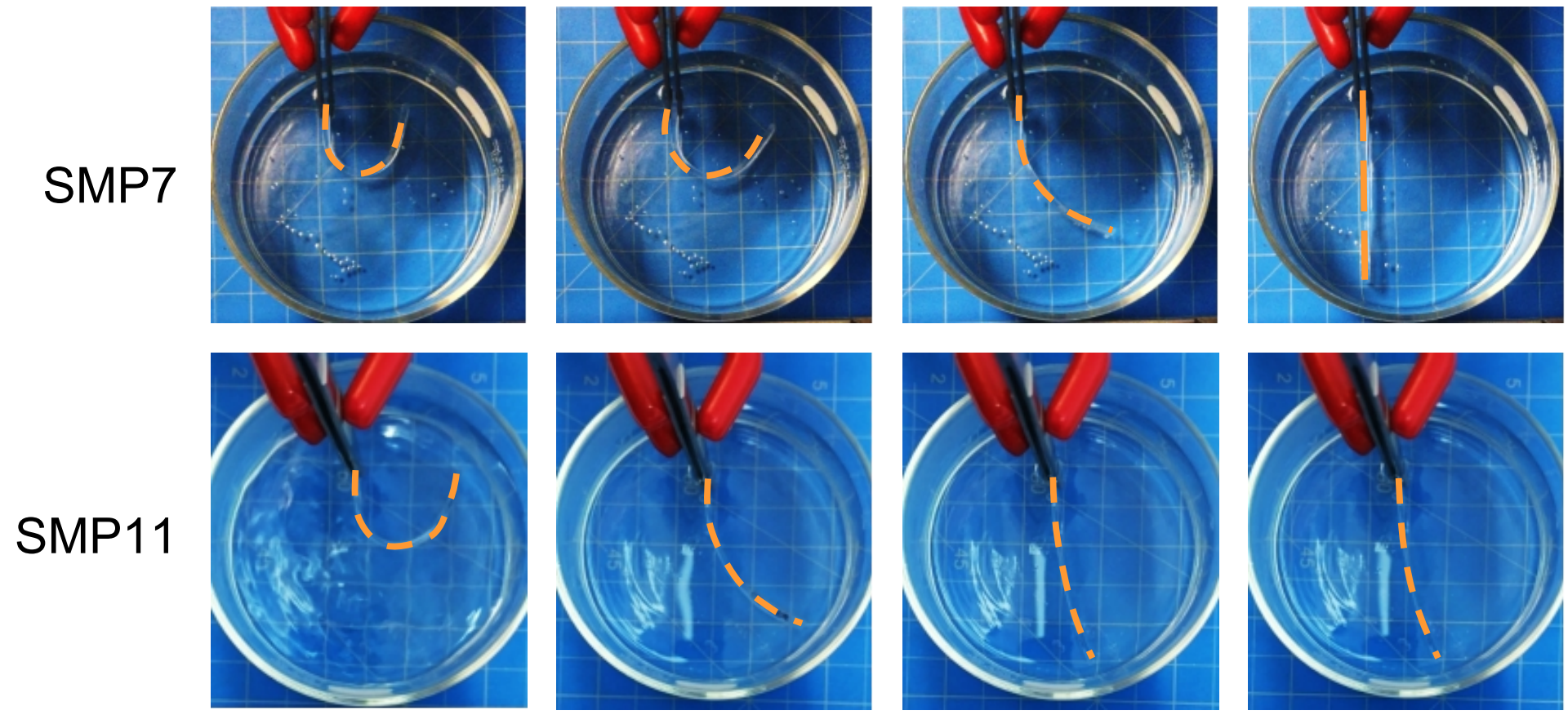

$\mathrm{t}=0 \mathrm{sec}$

$\mathrm{t}=2 \mathrm{sec}$

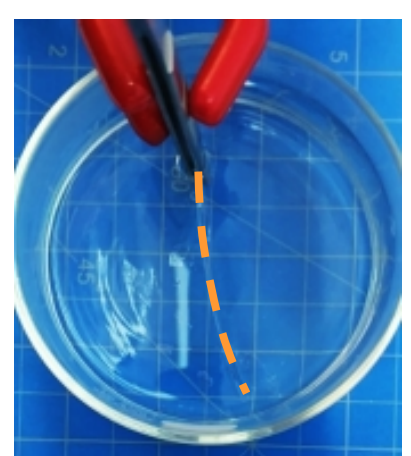

$t=4 \mathrm{sec}$

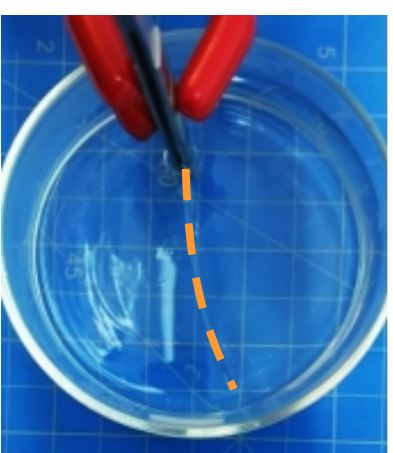

$\mathrm{t}=6 \mathrm{sec}$ 